\title{
Urban-Rural Synergies: An Explorative Study at the NUTS3 Level
}

\author{
Eveline van Leeuwen ${ }^{1}$
}

Published online: 11 September 2015

C The Author(s) 2015. This article is published with open access at Springerlink.com

\begin{abstract}
Regions are continually developing. Innovations in agricultural and industrial production affect urban and rural areas in different ways, and climate change and developments in transport and (tele)communication have strong effects on the interaction between them. Although urban and rural areas are often studied separately, systemic effects are clearly important when studying their interactions. This article aims to get a better understanding of the importance of urban-rural interaction between European regions. Therefore, a regional analysis using factor analysis and spatial correlation is used to show the presence and direction of urban-rural interactions. The results indicate that rural areas benefit from having more urban neighbors in terms of employment and employment growth as well as a stronger tourism sector. At the same time, urban areas with more rural neighbors experience a higher level of (relative) GDP growth. In addition, they are also related to higher levels of employment and population growth. Overall, the analysis shows that having more 'opposite' neighbors appears to be beneficial to both urban and rural regions. More research with more specific indicators, for example related to quality of life, as well as a more complete dataset, is necessary to confirm these conclusions.
\end{abstract}

Keywords Urban-rural interactions $\cdot$ Factor analysis $\cdot$ NUTS3 regions $\cdot$ Europe

\section{Introduction}

Rural and urban areas have traditionally enjoyed a relationship of interdependence: rural residents traded their redundant farm produce to their urban counterparts for complementary products and services, and as such contributed to the prosperity of many cities. On the other hand, the rural community often benefitted from the

Eveline van Leeuwen

e.s.van.leeuwen@vu.nl

1 VU University Amsterdam, Amsterdam, the Netherlands 
innovations that diffused from the cities. Since, the city population was also involved in food producing activities, it was here that many activities related to innovative agriculture started and were spread over the countryside (Jacobs 1969). Still today, urban and rural areas interact in terms of flows of products, people and communication. However, 'the regional science literature has traditionally taken for granted the urbanrural divide' (Van Leeuwen and Nijkamp 2006, p.283), and generally looked at cities and their hinterlands as independent entities. By not looking at interactions and dependencies between cities and their (wider) hinterlands, existing synergies are often overlooked. This happens even more so because the concepts of urban and rural are often loaded with connotations and images. When asking a group of around 50 international students about their top three images of urban and rural areas, at the top of the list for 'rural' can be found: agriculture, farmers and calm; for 'urban' the top three are pollution, busy and traffic. This is in line with what other researchers have found (Dahlström 1996). These connotations can seriously affect the mindset of both policymakers and researchers and as a result also their approach towards today's urban and rural areas.

Although urban and rural areas are often approached independently, systemic effects, that appear when the behavior of the system is very different from what could be envisaged from a straightforward examination of its components, are clearly important when studying urban-rural interactions. Fox et al. (1989) show how the local context, in terms of tangible characteristics such as accessibility and public services, as well as intangible aspects such as the tax structure, influence both the direction and magnitude of urban to rural spillovers. In line with this, Henry et al. (1997) emphasize that a regional rural development approach is useful for rural areas where urban-to-rural interactions are apparent. However, in areas with little urban-rural interactions, or where most economic (multiplier) effects end-up in the city (due to so-called 'backwash' effects), tailor-made rural development programs are more effective, especially when focusing on the improvement of quality of life (instead of 'simply promoting population or employment growth'). This illustrates that, when thinking about complexity as something that can be characterized by non-linearity, emergence, networks, etc., this certainly holds for regional development and urban-rural interactions. Clearly, regions are continually developing; innovations in agricultural and industrial production affect urban and rural areas in different ways, and climate change and developments in transport and (tele)communication have strong effects on urban-rural interactions. In this contribution, more light will be shed on different types of urban-rural interactions and their magnitude in European Union (EU) regions. In order to get an (almost) EU-wide overview, we combine a rich dataset of around $1000 \mathrm{EU}$ NUTS3 regions, with simple and straightforward statistical techniques, such as factor analysis and spatial correlation. In the next section, differences and similarities between urban and rural regions are described. The empirical part of the paper follows with the reporting of results of the factor analysis and spatial correlation. Then, different types of interactions that can explain the relationships that have been found in the empirical part are discussed and, in the final section, some conclusions are drawn.

\section{How Different are Urban and Rural Areas Today?}

Within several research fields, scientists are interested in urban and/or rural issues. However, the terminology used by, for example, geographers, social scientists, 
anthropologists or economists, often has different or multiple meanings. Often words used such as 'urban' and 'rural' are linked to a wide range of indicators, such as population density, settlement size, (agricultural) land-use, built-up environment, the amount of sealed surfaces, and cultural behaviors (McDonnell et al. 1997). In 1960, Dewey used eight concepts to understand the differences: heterogeneity, mobility, anonymity, female employment, class differences, impersonal relations, employment patterns and (exaggerated) importance of time. Clearly, these indicators are not-value free and reveal certain connotations. Today, we often use variables such as population (density), share of employment in agriculture and share of commuters to discern between more urban and more rural regions.

\section{What is a Successful Region?}

Increasingly, criticism arises towards the current ways of evaluating (regional) competitiveness and successfulness. The strong focus on economic growth, expressed in terms of (average) GDP per person put a strong focus on money, completely missing subtler and more important concepts as happiness and sustainability. These traditional indicators of GDP, population or, employment (growth) often result in more positive evaluation results for urban areas. However, as Isserman et al. (2009, p. 302) emphasize, 'growth and prosperity are not the same, although growth is often confounded with prosperity and is a common focus of local economic development initiatives'. Even if growth takes place, the benefits not necessarily accrue to the residents themselves; it might not even trickle down to the local economy. Recently, the focus started to shift, partly as a result of the notion that certain kinds of growth might not be infinite, and partly based on the idea that certain other things, such as health and happiness might be even more important. Although happiness and prosperity indicators are much more difficult to measure, several studies suggest that in terms of health, crime level, and happiness, rural areas outperform cities. As such, focusing on'place prosperity' might be 'a valuable new lens through which to examine issues of regional and rural development' (Isserman et al. 2009, p.301). However, this will require a change of mind, since research often focuses on issues as rural decline and poverty and thus the notion of 'rural prosperity' might be considered a paradox by many. Yet, as Isserman et al. (2009, p.301) conclude, 'hundreds of rural places in the US are more prosperous than the nation as a whole', as the research shows that these rural places outperform many cities in terms of unemployment rates, poverty rates, school dropout rates and, at the same time, offer better housing conditions.

Also the European Union (2011) provides interesting indicators. An example is the share of population that experiences severe material deprivation. This is measured by the people who cannot afford things such as a good meal every day, sufficient heating, a washing machine, colour TV, a telephone or a personal car. When looking at the EU, the highest levels of material deprivation are found in rural areas in new member states such as Bulgaria and Romania. In addition, in Eastern European countries such as Latvia, Hungary, Lithuania, Poland, Slovakia, as well as in Greece, deprivation prevails more in rural areas than in urban areas, but the gap is much smaller. But, in almost all (22) remaining (more developed) EU countries, severe material deprivation is most dominant in urban areas. Not surprisingly, people living in cities have better access to healthcare and communication infrastructure such as broadband. However, they also 
experience more crime, violence and vandalism: $23 \%$ of the urbanites versus $8 \%$ of the rural population reported this (European Union 2011).

\section{Rural Areas and Agriculture}

As the literature and the earlier mentioned international students showed, the first association that people have with rural areas is agriculture. An important reason for this is that agriculture indeed, to a large extent, determines rural landscapes. Until today, still $52 \%$ of total land use in the United States can be classified as agriculture (Nickerson et al. 2011), and $42 \%$ in the EU (Palmieri et al. 2011). However, from an economic point of view, several urban and rural areas are less different than often thought.

Figure 1 shows the share of employed persons in agriculture in urban, intermediate and rural EU NUTS3 regions. In all countries, this mostly takes place in rural areas. Of course, there is a clear differences between the new(er) member states like Romania, Bulgaria, Poland but also Greece and Portugal where more than $20 \%$ of the rural population employed persons works in the agricultural sector, and the old(er) member states like Sweden, Denmark, Belgium and The Netherlands were this is around $5 \%$. But, in several countries, a similar share of the population of intermediate regions is involved in agriculture, and also a smaller share of people living in urban areas. In The Netherlands, Czech Republic, Slovenia, Latvia and Poland between 2 and $4 \%$ of the urbanites is related to agricultural activities. In some of those countries, the difference between urban and rural regions in terms of people being employed in agriculture is only $3-4 \%$.

Van Leeuwen et al. (2010a) looked at how the level of concentration and specialization in agricultural production differs between urban and rural regions. They focus on 79 EU-9 regions in the period 1950-2000 in which they found that, in line with theories of Von Thünen (1826) and Losch (1954), for example, land-intensive and highyielding products are more often produced in the vicinity of cities. In addition, these concentration patterns intensified during the 50 years under study. Apart from the concentration of intensive agriculture in urban regions, Van Leeuwen et al. (2010a)

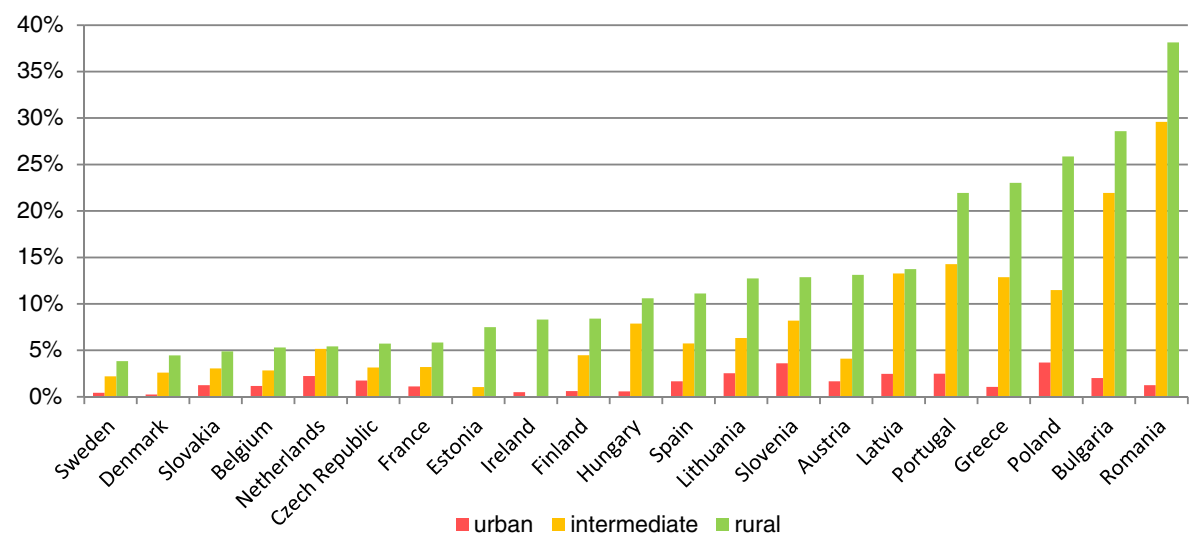

Fig. 1 Share of employed persons in agriculture in different types of regions in 2008. Source: Eurostat 
also found that urban areas tend to be more specialized in those kinds of activities; not only can most pig breeding activities be found near cities, it also is one of the main agricultural activities in those areas. ${ }^{1}$ On the other hand, the specialization level in dairy cattle appeared to be very similar in rural, intermediate and urban regions. This is thought to 'be due to the fact that dairy production is both relatively land and labor intensive, whereas the other studied products are either more labor intensive or more land intensive' (van Leeuwen et al. 2010a, p. 36). These findings show how the urban and rural spheres are often one intertwined system, linked to developments that affect entire society.

\section{Spatial Analysis of NUTS3 Regions}

To illustrate the presence and magnitude of urban-rural interactions, this section shows the evaluation of roughly 1000 European NUTS3 regions. The indicators of interest are related to regional performance: population, GDP, employment and tourism (growth). Through a factor analysis and correlation analysis, those are linked to a set of (own) regional characteristics; the numbers of years in the EU is used to distinguish between old and new member states. Furthermore, an indicator showing the share of dependent persons (young and old) in total population of a region is included to get a sense of the importance of demographic composition, which often differs significantly between urban and rural regions. Finally, an important variable is a dummy for regions that are considered urban or rural according to the new EU typology. For this typology Eurostat created clusters of urban grid cells with at least 5000 inhabitants and a minimum population density of 300 inhabitants per $\mathrm{km}^{2}$ (European Union 2010). All other cells are considered as rural. A NUTS3 region is classified as 'predominantly rural' if more than half of total population is located in rural grid cells; regions with 20 to $50 \%$ of their population in rural grid cells are classified as 'intermediate'; and regions are classified as 'predominantly urban' when less than a fifth of their inhabitants are found in rural grid cells (European Union 2010).

In the second part of this section the effect of having more urban or rural neighbors is evaluated by relating the share of different neighbors to the factors found. Figure 2 shows that data are collected from Eurostat for the years 2000 and 2009 and the regions are selected based on data availability, which includes minimal two-thirds of the total number of regions.

\section{Factor Analysis}

The analysis starts with a factor analysis of several variables that are related to quality of life and economic development. Factor analysis is a useful method to group explanatory variables into the so-called factors. We focus on the situation in 2009 and development levels for 2000-2009. Next to understanding what factors explain

\footnotetext{
${ }^{1}$ According to van Leeuwen et al. 2010a, this is thought to be enhanced by the EU's common agricultural policy that stimulated the use of imported feed components, favoring pig breeding activities in regions that are well connected to harbors (Blom 1992).
} 


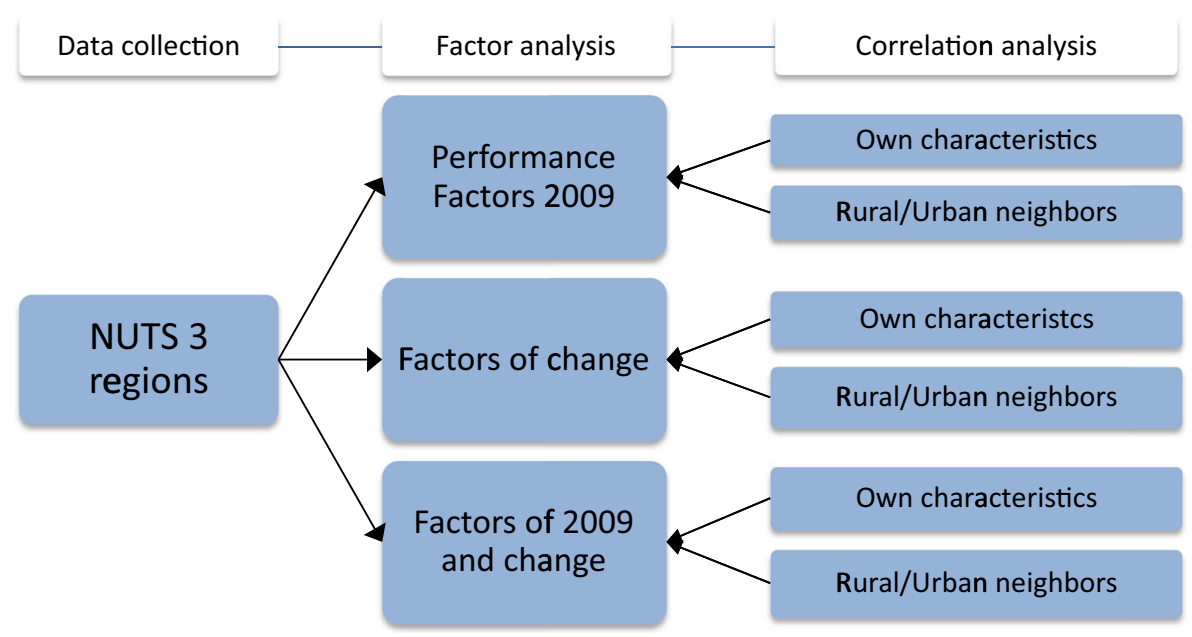

Fig. 2 Three main steps of the empirical approach

regional differences in Europe, a distinction is made between urban and rural areas and it is shown how this distinction relates to the factor scores.

To get a better idea of what factors affect regional development, we use a principal component analysis with a varimax rotation to ease the interpretation of the (uncorrelated) factors (see e.g. Hair et al. 1995). For the interpretation of the factors we focus on components with a loading higher than 0.4. The Kaiser-Meyer-Olkin (KMO) measure of sampling indicates a reasonable good fit of, in particular, the final model. ${ }^{2}$ In a second step, the factors are correlated with explanatory variables to see if there are any significant (positive or negative) relationships.

\section{Current Situation}

The first factor analysis includes variables describing the current situation: employment per person in the working age (wpp), GDP per person, number of tourist bed places per person and jobs in agriculture per person in the working age. The analysis includes 1071 regions and the two factors explain in total $65 \%$ of the variance (Table 1 ). The first factor can be explained as low levels of GDP/pp and high share of employment in the agricultural sector. When looking at the correlations, it appears that this often holds for regions in new(er) member states and rural areas. In addition, these regions are related to large(r) shares of young and old (dependent) people. The second factor can be explained by a high level of jobs and a large number of beds for tourists. The correlations show that areas in old(er) member states, as well as rural areas are positively related to this factor. Furthermore, these regions are characterized by more people in the working age (less dependent persons).

\footnotetext{
2 The first two models show a relatively low KMO value and should be seen as intermediate steps to reach the final factor model. The large dataset and high factor loadings are reasons to include the tables in the paper.
} 
Table 1 Factor analysis of the current (2009) situation

\begin{tabular}{|c|c|c|}
\hline & Components & \\
\hline Variance explained & $37 \%$ & $29 \%$ \\
\hline Summary & Low GDP and high Agri-employment & High employment and tourism \\
\hline Beds/pp & & 0.555 \\
\hline $\mathrm{GDP} / \mathrm{pp}$ & -0828 & \\
\hline Employment/wpp & & 0.827 \\
\hline \multirow[t]{2}{*}{ Agri-employment/wpp } & 0,857 & \\
\hline & Correlations & \\
\hline Years in the EU & $-0.615^{* *}$ & $0.087 * *$ \\
\hline Old-young/rest & $0.197 * *$ & $-0.074 *$ \\
\hline Urban & $-0.305^{* *}$ & $-0.090 * *$ \\
\hline Rural & $0.371 * *$ & $0.140 * *$ \\
\hline
\end{tabular}

**Correlation is significant at the 0.01 level (2-tailed)*Correlation is significant at the 0.05 level (2-tailed)

\section{Growth}

The second factor analysis deals with growth variables. For 937 regions this information is available. The two factors explain in total $63 \%$ of the variance (Table 2). The first factor can be explained as regions with population and employment growth. The second factor is related to regions with a high GDP growth, as well as a positive growth in numbers of tourist bed places.

The correlations nicely show that the first growth factor is more related to old member states and the second one to newer ones. In addition, growth in population and employment (factor 1) is more often found in urban regions and in areas with less

Table 2 Factor analysis of growth variables, 2000-2009

\begin{tabular}{|c|c|c|}
\hline & Components & \\
\hline Variance explained & $37 \%$ & $26 \%$ \\
\hline Summary & Growth in population and employment & Growth in GDP and tourism \\
\hline GDP/pp growth & & 0.713 \\
\hline Bed/pp places growth & & 0.692 \\
\hline Population growth & 0.810 & \\
\hline \multirow[t]{2}{*}{ Employment/wpp growth } & 0.764 & \\
\hline & Correlations & \\
\hline Years in the EU & $0.177 * *$ & $-0.526^{* *}$ \\
\hline Old-young/rest & $-0.090 * *$ & $0.110^{* *}$ \\
\hline Urban & $0.177 * *$ & \\
\hline Rural & $-0.175^{* *}$ & $0.082 *$ \\
\hline
\end{tabular}

**Correlation is significant at the 0.01 level (2-tailed)*Correlation is significant at the 0.05 level (2-tailed) 
dependent people, while growth in GDP and the tourism sector is positively related to rural regions.

\section{All Variables}

The third model combines the above shown variables about growth and the current situation. It results in three factors that explain $63 \%$ of the variance of 937 regions in the dataset (Table 3). The first and largest factor can be explained as regions with low levels of GDP, relatively many jobs in the agricultural sector and high GDP/pp growth. Not surprisingly, this relates to new(er) member state regions as well as to rural areas. This can indicate a catching-up effect of in particular rural areas in new member-states. The second factor includes areas with high levels of employment, as well as high levels of employment growth. Interestingly, this factor does not relate to number of years in the EU, or to the urban and rural character of the regions. Apparently, it can be found everywhere. The third factor is clearly related to tourism and growth in this sector. It is correlated with older member states.

$\mathrm{KMO}=0.62$.

\section{Synergies: Effects of Neighbors}

Until now, we only looked at the independent regions, not taking into account the effect of neighbors and any possible synergy. An interesting question however is how urban areas affect rural areas and vice versa. Therefore we calculated for each (NUTS3) region what the share of urban and rural neighbors is of its total (including

Table 3 Factor analysis of growth and current state variables

\begin{tabular}{|c|c|c|c|}
\hline & Components & & \\
\hline Variance explained & $27 \%$ & $20 \%$ & $16 \%$ \\
\hline Summary & $\begin{array}{l}\text { Agriculture and Low GDP } \\
\text { but high GDP growth }\end{array}$ & High employment (growth) & Tourism (growth) \\
\hline Beds/pp & & & 0.729 \\
\hline $\mathrm{GDP} / \mathrm{pp}$ & -0.784 & & \\
\hline Employment/wpp & & 0.828 & \\
\hline Agri-employment/wpp & 0.804 & & \\
\hline Bed/pp growth & & & 0.764 \\
\hline GDP/pp growth & 0.770 & & \\
\hline Employment/wpp growth & & 0.776 & \\
\hline \multirow[t]{2}{*}{ Population growth } & -0.466 & 0.443 & \\
\hline & Correlations & & \\
\hline Years in the EU & $-0.675^{* *}$ & & $-0.105^{* *}$ \\
\hline Old-young/rest & $0.219 * *$ & & \\
\hline Urban & $-0.296 * *$ & & \\
\hline Rural & $0.336^{* *}$ & & \\
\hline
\end{tabular}

**Correlation is significant at the 0.01 level (2-tailed)*Correlation is significant at the 0.05 level (2-tailed) 
intermediate) number of neighbors. We used a Gabriel weights matrix to determine who is a neighbor of whom. In brief, a Gabriel plot (Gabriel and Sokal 1969; Matula and Sokal 1980) connects all points that have no intervening neighbour. Although this does not result in a perfect weights matrix, it has the advantage that also the smaller regions in for example France, The Netherlands and Germany have a reasonable (not too many) number of neighbors. We included the 927 regions for which all variables are available, of which most have four or five neighbors and two have only one neighbor and another two eight neighbors. In addition, we make a distinction between urban and rural regions. The dataset of 937 regions for which all information is available includes 217 urban regions and 356 rural regions. The share of rural neighbors of urban regions ranges from 0 to $100 \%$, with an average of $20 \%$. In addition, they have around $40 \%$ urban neighbors. Rural areas have on average more rural neighbors and less urban ones: 44 and $11 \%$. Table 4 shows the Pearson correlations with the single variables used so far.

In general, having (more) rural neighbors is correlated with lower levels of GDP and having more urban neighbors with higher levels. GDP growth, on the other hand, is positively related to having more rural neighbors, in particular for urban areas. In addition, more rural neighbors for urban regions is also correlated with higher levels of employment and population growth, while having more urban neighbors (and possibly more competition) relates to lower levels of growth. Also for rural areas, it is the diversity (i.e. the share of urban neighbors) that shows a positive effect on different types of growth. Although this table only shows bivariate relations, patterns of synergy seem to be apparent.

Not surprisingly the level of employment in agriculture is positively correlated with having a larger share of rural neighbors. However, this effect seems to be mainly related to urban areas: urban regions with more rural neighbors are correlated with higher levels of agri-employment, while urban regions in a more urban context have lower levels of jobs in agriculture.

Finally, we also look at the correlation between the three (total) factors and the share of urban and rural neighbors the regions have (see Table 5). For all regions, and in

Table 4 Correlation between current situation and growth variables and the share of urban or rural neighbors for different types of regions

\begin{tabular}{|c|c|c|c|c|c|c|}
\hline \multirow[b]{2}{*}{ Type of neighbors } & \multicolumn{2}{|l|}{ All regions } & \multicolumn{2}{|c|}{ Rural regions } & \multicolumn{2}{|c|}{ Urban regions } \\
\hline & Rural & Urban & Rural & Urban & Rural & Urban \\
\hline Beds/pp & & $-0.133 * *$ & $-0.228 * *$ & & & \\
\hline GDP/pp & $-0.207 * *$ & $0.242 * *$ & & & $-0.217 * *$ & $0.179 * *$ \\
\hline \multicolumn{7}{|l|}{ Employment/wpp } \\
\hline Agri-employment/wpp & $0.231 * *$ & $-0.253 * *$ & & & $0.385^{* *}$ & $-0.308 * *$ \\
\hline Bed/pp growth & $-0.100 * *$ & $0.131 * *$ & & $0.116^{*}$ & & \\
\hline GDP/pp growth & $0.249 * *$ & $-0.232 * *$ & & & $0.436^{* *}$ & $-0.343 * *$ \\
\hline Employment/wpp growth & $-0.065^{*}$ & & & $0.107 *$ & $0.288 * *$ & $-0.262 * *$ \\
\hline Population growth & $-0.063^{*}$ & $0.187 * *$ & & $0.292 * *$ & $0.262 * *$ & $-0.154^{*}$ \\
\hline
\end{tabular}

**Correlation is significant at the 0.01 level (2-tailed)*Correlation is significant at the 0.05 level (2-tailed) 
particular the urban ones the first factor of low GDP but high GDP growth is related to regions being located in a rural context with more rural neighbors. Although Table 3 showed that factor 1 is correlated with rural regions, this table shows that also the urban areas seem to benefit from the catching up of these areas. Furthermore, it appears that urban areas with more rural counterparts are positively correlated with employment growth (factor T2). At the same time, rural areas benefit from having more urban neighbors in terms of employment and employment growth. Also the third factor that deals with the tourist sector shows the importance of geographical diversity and related synergy between the two types of regions. Rural areas in a more urban context benefit by having a stronger tourist sector in terms of bed places, while rural areas with more similar neighbors score lower on this factor.

\section{Summary}

This analysis shows how urban and rural areas differ, using 'traditional' indicators of growth and the current situation. In addition, urban-rural interactions in terms of correlations between the indicators and factors are shown. In terms of the current situation, urban regions, mostly in the old(er) member states have higher levels of employment and GDP. However, if the regions are in new(er) member states, often it is the rural ones that have the strongest growth in GDP. When performing a factor analyses, three types of regions stand out: more agricultural regions with low levels of GDP but strong GDP growth; regions that do well in terms of employment (growth); and regions characterized by tourism (growth).

When looking at possible synergy effects by taking into account the share of different types of neighboring regions, this analysis shows clearly that having a higher share of 'other' neighbors is positively correlated with growth, while having more similar neighbors gives a negative correlation. Also when looking at how urban areas are affected by rural neighbors the most important conclusions are related to the growth related variables. First of all, urban areas with more rural neighbors experience a higher level of (relative) GDP growth. In addition, they are also related to higher levels of employment and population growth. However, they are also more likely to face a lower GDP level. At the same time, also rural regions appear to benefit from being located in a more urban and thus diverse

Table 5 Correlations between the factors and the share of urban and rural neighbors for different types of regions

\begin{tabular}{|c|c|c|c|c|c|c|c|}
\hline \multirow[t]{2}{*}{ Factor } & & \multicolumn{2}{|c|}{ All regions } & \multicolumn{2}{|c|}{ Rural regions } & \multicolumn{2}{|c|}{ Urban regions } \\
\hline & $\begin{array}{l}\text { Type of neighbors } \\
\text { Factor description }\end{array}$ & Rural & Urban & Rural & Urban & Rural & Urban \\
\hline $\mathrm{T} 1$ & $\begin{array}{l}\text { Agriculture and Low GDP, but high } \\
\text { GDP growth }\end{array}$ & $0.260 * *$ & $-0.324 * *$ & & & $0.342 * *$ & $-0.278^{* *}$ \\
\hline $\mathrm{T} 2$ & Employment (growth) & & & & $0.116^{*}$ & $0.273 * *$ & $-0.233 * *$ \\
\hline $\mathrm{T} 3$ & Tourism (growth) & & & $-0.185^{* *}$ & $0.138 * *$ & & \\
\hline
\end{tabular}

**Correlation is significant at the 0.01 level (2-tailed)*Correlation is significant at the 0.05 level (2-tailed) 
context, in particular related to the tourist sector and in terms of employment growth.

\section{Drivers of Interaction and Synergy}

Now that Spatial Analysis of NUTS3 Regions section showed that urban-rural interactions are important and that synergy seems to take place between both kinds of regions, this Section will go deeper into how these interactions might take place. Apparently, still today urban areas benefit from rural ones and vice versa. As the factor analyses showed, static and dynamic characteristics of regions are often intertwined: areas with low(er) levels of GDP are more likely to have higher growth levels while, on the other hand, there are regions in which the tourism industry is (already) important and is growing as well. In this section, we will take a closer look at current drivers of urban-rural interactions, such as flows of people, flows of goods, communication flows and ecosystem services.

\section{Flows of People}

In many developed countries the urban-rural fringe is increasingly taken over by the urban population. People from the city buy houses in nearby smaller towns, while commuting to their urban jobs. Other citizens like to spend their increasing leisure time in 'their backyard', facilitated by bike paths, running tracks and golf courses (van Leeuwen and Nijkamp 2006). Often, the urbanites and their preferences and conditions have a strong impact on the rural environment in terms of the minimum level of communication and transport infrastructure necessary, or the level of maintenance of the landscape. Clearly, there are benefits from these interactions to the rural population as well. Therefore, especially for rural entrepreneurs, it can be beneficial to strengthen the relationships with their urban 'customers'. 'They invite urbanites to buy their products and services, such as homemade products and camping opportunities, and they use the city for (part-time) jobs, specialized education or cultural entertainment' (van Leeuwen and Nijkamp 2006, p.301).

\section{Commuters}

According to Partridge et al. (2010, p.303), 'commuting ties between rural places of residence and urban places of employment are among the most visible forms of ruralurban integration'. As the analysis of the NUTS3 regions showed as well (Tables 4 and 5), access to urban employment is often very important for population and employment growth in both urban and rural regions. Reasons to move to rural areas are often related to lifestyle and quality of life, while keeping their urban engagement is an important prerequisite, as Partridge et al. (2010) findings show for Canada. This also appears to be the case in Sweden. Westlund (2002) shows that, when focusing on rural population growth in Sweden, which mainly takes place around metropolitan areas and regional capitals, important factors determining rural population development at the municipality level are the availability of jobs, (average) income levels and average property values. 
As such, commuting can be related to labor conditions and living conditions. Therefore, we can define four reasons: a shortage of jobs in rural areas, a shortage of workforce in urban areas, preferred living environment in rural areas or a preferred living environment in cities. When migration of urban people to rural residences takes place, rural population growth can be considered a primary driver of rural to urban commuting (Rouwendal and Meijer 2001). Another driver can be rural restructuring through urban industry moving to nearby rural areas due to lower transport and land prices. According to Renkow and Hoover (2000) in North Carolina, trends in out commuting are more related to deconcentration. Nevertheless, although commuting between cities and (accessible) rural areas is important, most commuter movements take place between urban areas or between rural areas (Harris et al. 2008).

\section{Tourists and Visitors}

When people plan to take some time off and to enjoy other places, they have to choose a destination for their activities. Different reasons why people take a vacation, as well as different states of mind and motivations lead tourist behavior in certain directions (Nahab 1975). Nicolau and Más (2008, p.1028) consider four reasons: the search for 'amusement'; interest in 'broadening culture'; longing for 'discovering new places'; and the search for 'tranquility'. Obviously, this can take place in different kinds of environments with urban and rural areas offering different attractions and benefits. When looking at the concentration of (tourist) bed-places in Europe high levels are found in both urban and rural places. In Italy, for example, Rome is an important touristic attraction, and so is the rural region of Tuscany. Also the two million tourists who visit Phillip Island in Australia each year mainly visit this place to enjoy the beautiful natural environment (Weaver and Lawton 2001).

The resulting flows of visitors affect urban-rural interactions in three important ways: through the transfer of income from one place to the other; through the exchange of experiences between visitors and hosts; and through the exchange of (historical) cultural values. The transfer of income not only affects the tourism sector, but also supplying sectors such as the retail sector and transport sector. Through the use of often-local labor and products, the wider economic (multiplier) effect of tourism expenditures is relatively high (Van Leeuwen 2010). Furthermore, the exchange of experiences can result in decreasing cultural differences and the exchange of cultural values in increasing awareness of the importance of natural and historical heritage and in opportunities to re-evaluate the willingness to preserve them.

\section{Flows of Goods}

Cities are often seen as 'engines of economic growth and global trade' (Rees and Wackernagel 1996). This results, on the one hand, in an urban to rural energy and (raw) material dependence. On the other hand, since trade can be seen as a way to export local surpluses, it allows areas to use the related earned incomes to pay for the imports of locally scarce resources. By doing so, these flows of goods (and energy) increase incomes and carrying capacity in both urban and rural trading regions (Rees and Wackernagel 1996). Today, with the increasing transport of agricultural products, the physical relations between urban areas and their hinterland are less clear to most 
people. Many (intermediate) products are imported from all over the world. Of course, urbanites need to be fed and many important inputs for urban manufacturing activities, such as metals, fibers and energy are harvested in rural areas. However, not seeing (or knowing) where the products originate from can easily result in over exploitation of land and labor in low-cost developing countries and in negative externalities of the many transport movements. This does not only hold for flows between urban and rural areas, but also for flows of goods between developing and developed rural regions.

When looking at a slightly lower scale level, of towns and their direct hinterlands, the (spatial) flows of people overlap with inter-linkages between sectors (Tacoli 2003). Earlier work of the author shows how urban-rural linkages in terms of trade of products and services have higher (economic) benefits for the towns. Based on a local interregional input-output analysis of 30 European towns of between 10,000 and 20,000 inhabitants and their direct hinterland ( $7 \mathrm{~km}$ radius), hinterland multipliers appear to be larger than town multipliers, but the share that ends-up in the town economy exceeds the benefits of the rural areas (Van Leeuwen 2010). It shows how rural (hinterland) areas benefit from the towns for inputs and facilities as well as jobs and how towns benefit from hinterlands in terms of sales: the effects go both ways.

\section{Flows of Communication}

Increasingly, (successful) economic and social transactions depend on access to relevant and specific information, and in particular, access to the Internet (Warren 2007). This does not only hold for knowledge-intensive industries but for most actors in society since all kinds of 'agents', such as large firms, NGOs; SMEs and even governmental organizations and individuals increasingly depend on digital diffusion of information (Warren 2007). Internet access allows firms to innovate in terms of interaction with clients and partners, but also to update their production process. Two important consequences of this are increasing developments in teleworking and the growth of 'out sourcing' of several services (Moseley and Owen 2008. Increasingly, rural areas have access as well to facilities such as online shops, online baking, the online governmental office window and online education and training (Malcolm and Owen 2008). This means that services can be obtained from everywhere: the growing online retail sales shows how for many people, the Internet is a useful and important marketplace.

For (certain) businesses, this means they do not necessarily need to be next to their customers anymore and vice versa. Of course, the availability of Internet access is crucial in this. This is important because, apart from information acquisition and online purchases, the Internet also allows interaction with different relevant stakeholders in the broad context of governance (Warren 2007). In terms of urban-rural interactions, Internet reduces traditional barriers (of distance, appearance and even of dialects) to such interaction. On the Internet we are all the same; people cannot see who is from the city or the countryside, and everyone has access to the same information. This highlights the importance of good Internet access in lagging (rural) regions, to prevent them 'catching up' with more successful regions. Furthermore, additional attention of non-users is indispensable, as these often include the most vulnerable people of society. To this extent, 'the shrinking of the 'digital divide' (and particularly the increased availability of broadband Internet) is very important' (Warren 2007, p.374). 


\section{Ecosystem Services}

Some of the above-described flows can directly be related to ecosystem services. Ecosystem services can be described as 'benefits the human population derives, directly or indirectly, from ecosystem functions' (Costanza et al. 1997, p.253). Those functions are often grouped in categories with use and non-use value. The first category consists of resources that are used directly such as water, agricultural products but also clean air, renewable and fossil energy and natural amenities. Furthermore, indirect use values come from regulating services, such as water purification and flood prevention (through natural dikes or water retention). Examples of non-use values are option and bequest values (services that we could use in the future or that next generation could use) and existing values (the value that is related to the existence of e.g. whales and pandas).

Ecosystem services enhance urban-rural interactions because often the city benefits from (mostly) rural ecosystems services. For some of it, the rural areas receive monetary compensation, such as for flood protection. Many larger urban centres are located near river and sea harbours. In new Orleans, for example, coastal wetlands have slowed down hurricanes and other storms, reduced storm surges and thus protected the city. The destruction of these wetlands resulted in large open water bodies that even reinforce the danger from hurricanes and other storms (Guerrya et al. 2012). In Europe, several cities are protected from flooding by water retention areas that in case of emergency temporary store redundant rain/river water. Because of a lack of space in cities, those retention areas are mainly located in the upstream countryside.

Another interesting example is urban agriculture. Armstrong (2000), by studying community gardens in New York, found that community gardens improve well-being and social networks, and are beneficial for one's health. Although it has been considered old-fashioned for a long time, today's increasingly young families are getting interested as well (Garnett 1999). Another example of urban 'agriculture' can be found in the Dutch urban-rural fringe were almost 1000 farms exist, which take care of mentally challenged people, stressed managers, ex-inmates, etc. Such so-called noninstitutional health farming can significantly contribute to the local economy. In The Netherlands this is estimated to be around $€ 72$ million in 2008 (van Leeuwen et al. 2010b).

Also, other ecosystem services, such as the provision of renewable energy, clean water, inputs for (new) medicines and the provision of food and fiber, are often 'produced' in rural areas and to a large extent consumed in urban areas. Finally, the more 'obvious' ecosystem services such as clean air, quietness and natural landscapes appear to be important pull-factors to urban residents to visit or migrate to more rural areas.

\section{Conclusions}

The aim of this paper is to shed more light on contemporary urban-rural synergies, by focusing on EU NUTS3 regions and their 2009 state levels and 2000-2009 socioeconomic growth levels. Too often, the urban and the rural are looked upon as if they are two different and separate systems, while in reality they are closely linked. Interactions are increasing and differences seem to decrease in many developed 
countries. Rural areas become less dependent on agriculture and some (intensive) types of agricultural activities take place in intermediate and urban regions: in some countries the difference between the urban and rural share of labor in agriculture is less than $5 \%$.

Although, urban-rural interactions are often thought to be less important today, this is not the case. Of course, some of the interactions became less local, and hence less visible. This is, for example, the case for the provision of food and fibre. Still a large part of the (extensive) production of food and fibre for cities takes place in rural areas, however, generally it is not produced nearby. On the other hand, commuting patterns, and the often related congested roads during peak-hours, clearly show how cities are important locations for jobs and to a certain extent depend on rural labor.

In this article an explorative analysis has been performed, focusing on dimension reduction in terms of factor analyses and bivariate relations. The explorative study of the European NUTS3 regions indicates that urban-rural synergies are potentially quite important. Rural areas benefit from having more urban neighbors in terms of employment and employment growth. Furthermore, rural regions in a more urban context benefit from this by having a stronger tourist sector in terms of (growth of) bed places, while rural areas with more similar neighbors score lower on this factor. For certain urban areas, we find that those regions with more rural neighbors experience a higher level of (relative) GDP growth. In addition, they are also related to higher levels of employment and population growth. Unfortunately, at the same time they are more likely to face a lower GDP level. All in all, the analysis showed that having more 'opposite' neighbors appears to be beneficial to both urban and rural regions.

There are several important trends that will intensify urban-rural interactions in the future. First of all, the increasing flexibility in terms of workplace (even on a day by day basis) due to increased mobility and Internet applications allow more people to live in the countryside. Increased communication through social media and other online applications will decrease urban-rural cultural differences even further, in particular under the younger residents. How this will affect interactions is yet to be seen, but it is likely that urban and rural areas will become more similar, in particular in the more accessible regions. Furthermore, scale enlargement in public and commercial services are likely to increase the dependency of rural inhabitants on the city as a place for physical contacts. Again, digital developments might reduce the impact, but physical contacts (always) remain important. Finally, expected climate change will in many places result in a stronger dependency of urban areas on (rural) ecosystem services. In particular flood risk (since a relatively large number of cities is located near rivers or at the coast) and the effects of high temperatures and droughts will have an important impact on urban areas.

Thus, better understanding of the needs of both urban and rural populations, the magnitude of interactions between them and the detection of vulnerable groups are important research topics for the future. In addition, more extensive analyses focusing on cause and effect relationships are likely to result in very welcome contributions to the research field.

Open Access This article is distributed under the terms of the Creative Commons Attribution 4.0 International License (http://creativecommons.org/licenses/by/4.0/), which permits unrestricted use, distribution, and reproduction in any medium, provided you give appropriate credit to the original author(s) and the source, provide a link to the Creative Commons license, and indicate if changes were made. 


\section{References}

Armstrong, D. (2000). A survey of community gardens in upstate New York: implications for health promotion and community development. Health \& Place, 6, 319-327.

Blom, J. C. (1992). An evaluation of EC cereal policy instruments. Mededeling 457. The Hague: LEI.

Costanza, R., d'Arge, R., de Groot, R., Farber, S., Grasso, M., Hannon, B., Limburg, K., Naeem, S., O’Neill, R., Paruelo, J., et al. (1997). The value of the world's ecosystem services and natural capital. Nature, 387, $253-261$.

Dahlström, M. (1996). Young women in a male periphery - experiences from the Scandinavian north. Journal of Rural Studies, 12, 259-271.

Dewey, R. (1960). The rural-urban continuum: real but relatively unimportant. American Journal of Sociology, 66, 60-66.

Union, E. (2010). Eurostat regional yearbook 2010. Belgium:Eurostat Statistical Books.

Union, E. (2011). Eurostat regional yearbook 2011. Belgium:Eurostat Statistical Books.

Fox, W. F., Herzog Jr., H. W., \& Schlottman, A. M. (1989). Metropolitan fiscal structure and migration. Journal of Regional Science, 29, 523-536.

Gabriel, K. R., \& Sokal, R. R. (1969). A new statistical approach to geographic variation analysis. Systematic Biology, 18(3), 259-278.

Garnett, T. (1999). Urban agriculture in London: rethinking our food economy, paper presented at the international workshop 'growing cities growing food' in Havana. Cuba.

Guerrya, A. D., Ruckelshausa, M. H., Arkemaa, K. K., Bernhardta, J. R., Guannela, G., Kima, C.-K., Marsikb, M., Papenfusa, M., Tofta, J. E., Verutesa, G., et al. (2012). Modeling benefits from nature: using ecosystem services to inform coastal and marine spatial planning. International Journal of Biodiversity Science Ecosystem Services \& Management, iFirst, 1-15.

Hair, J. F., Anderson, R. E., Tathamand, R. L., \& Black, W. C. (1995). Multivariate data analysis with readings (4th ed., ). New Jersey:Prentice-Hall International.

Harris, S., Alasia, A., \& Bollman, R. D. (2008). Rural commuting. Perspectives on Labour and Income, 9(11), 13-21.

Henry, M. S., Barkley, D. L., \& Bao, S. (1997). The hinterland's stake in metropolitan growth: evidence from selected southern regions. Journal of Regional Science, 37(3), 479-501.

Isserman, A. M., Feser, E., \& Warren, D. E. (2009). Why some rural places prosper and others do not. International Regional Science Review, 32(3), 300-342.

Jacobs, J. (1969). The economy of cities. New York:Random House.

Losch, A. (1954). The economics of location. Translated from the second revised edition. New Haven, Conn: Yale University Press.

Malcolm, J. M., \& Owen, S. (2008). The future of services in rural England: the drivers of change and a scenario for 2015. Progress in Planning, 69(3), 93-130.

Matula, D. W., \& Sokal, R. R. (1980). Properties of Gabriel graphs relevant to geographic variation research and the clustering of points in the plane. Geographical Analysis, 12(3), 205-222.

McDonnell, M. J., Pickett, S., Groffman, P., Bohlen, P., Pouyat, R. V., Zipperer, W. C., Parmelee, R. W., Carreiro, M. M., \& Medley, K. (1997). Ecosystem processes along an urban-to-rural gradient. Urban Ecosystems, 1(1), 21-36.

Moseley, M. J., \& Owen, S. (2008). The future of services in rural England: the drivers of change and a scenario for 2015. Progress in Planning, 69(3), 93-130.

Nahab, S. (1975). Tourism management. London:Tourism International Press.

Nickerson, C., Ebel, R., Borchers, A., \& Carriazo, F. (2011). Major uses of land in the United States, 2007. Economic Information Bulletin, No. (EIB-89).

Nicolau, J. L., \& Más, F. J. (2008). Sequential choice behavior: going on vacation and type of destination. Tourism Management, 29(5), 1023-1034.

Palmieri, A., Dominici, P., Kasanko, M., \& Martino, L. (2011). Diversified landscape structure in the EU member states landscape indicators from the LUCAS1 2009 survey. Eurostat:Statistics in Focus.

Partridge, M. D., Ali, K., \& Olfert, M. (2010). Rural-to-urban commuting: three degrees of integration. Growth and Change, 41(2), 303-335.

Rees, W., \& Wackernagel, M. (1996). Urban ecological footprints: why cities cannot be sustainable- and why they are a key to sustainability. Environmental Impact Assessment Review, 16, 223-248. 
Renkow, M., \& Hoover, D. (2000). Commuting, migration, and rural-urban population dynamics. Journal of Regional Science, 40(2), 261-287.

Rouwendal, J., \& Meijer, E. (2001). Preferences for housing, jobs and commuting: a mixed logit analysis. Journal of Regional Science, 41(3), 475-505.

Tacoli, C. (2003). The links between urban and rural development. Environment and Urbanization, $15(1), 3-12$.

Van Leeuwen, E. S. (2010). Urban-rural interactions: towns as focus points in rural development. Contributions to economics. Heidelberg:Springer.

van Leeuwen, E. S., \& Nijkamp, P. (2006). The urban-rural nexus - a study on extended urbanization and the hinterland. Studies in Regional Science, 36(2), 283-303.

van Leeuwen, E. S., Terluin, I. J., \& Strijker, D. (2010a). Regional concentration and specialisation in agricultural activities in EU-9 regions, 1950-2000. European Spatial Research \& Policy, 17(1), 23-39.

van Leeuwen, E. S., Nijkamp, P., \& de Noronha Vaz, T. (2010b). The multifunctional use of urban greenspace. International Journal of Agricultural Sustainability, 8(1-2), 20-25.

Von Thünen, J.H. (1826). Der Isolierte Staat in Beziehung auf Landschaft und Nationalökonomie. Translated by C.M. Wartenberg (1966). Von thünen's isolated state. Pergamon Press, Oxford.

Warren, M. (2007). The digital vicious cycle: links between social disadvantage and digital exclusion in rural areas. Telecommunications Policy, 31(6-7), 374-388.

Weaver, D. B., \& Lawton, L. J. (2001). Resident perceptions in the urban-rural fringe. Annals of Tourism Research, 28(2), 439-458.

Westlund, H. (2002). An unplanned green wave: settlement patterns in Sweden during the 1990s. Environment and Planning A, 34, 1395-1410. 